\title{
Developmental Psycho- Neurological Research Trends and Their Importance for Reassessing Key Decision-Making Assumptions for Children, Adolescents, and Young Adults in Juvenile/Youth and Adult Criminal Justice Systems
}

\author{
RAYMOND CORRADO AND JEFFREY MATHESIUS*
}

\section{Introduction}

A key premise of Western criminal law and justice is that behavior with certain obvious exceptions such as severe psychosis is the product of rational choice and free will. Individuals, therefore, choose whether or not to commit a criminal offence based, typically, on an analysis of the risks and benefits. Historically, it is the fundamental differences between juveniles and adults with regards to the legal principle of responsibility (i.e., extent of free will/rational choice) that justified the existence of distinctive criminal laws. This article utilizes current empirical research to assess the validity of the central assumptions underlying the legal decision-making process based on this adult-juvenile distinction.

The minimum and maximum age of the juvenile justice systems in several countries has been an increasingly contentious issue, both 'scientifically' and politically. In the later

Ray Corrado is a professor at the School of Criminology at Simon Fraser University and a visiting professor at the Faculty of Psychology of the University of Bergen. Jeffrey Mathesius is a doctorate student at the School of Criminology at Simon Fraser University. The authors would like to thank Dr. Annika Suominen for her assistance on the current paper. 
realm, proponents for lowering the minimum age assert the need to hold violent youth accountable and to deter them and other youth from such crimes. Opponents counter that adolescents and children, for a variety of reasons, lack the necessary legal responsibility to be criminally punished. ${ }^{1}$ Frequently, it is the rare incidents of extreme violence that provoke this debate. For example, in August 2013 a 10-year-old boy beat to death Lee Bonneau, a 6-year-old, on the Kahkewistahaw First Nation reserve in the province of Saskatchewan, Canada. ${ }^{2}$ The minimum age of criminal responsibility across all provinces in Canada is 12 years of age, and, consequently, the 10-year-old cannot be charged under Canada's Youth Criminal Justice Act. In contrast, in 1993 in the town of Bootle in northern England, Jon Venables and Robert Thompson, both 10 years old at the time, abducted 2-year-old James Bulger from a public shopping mall and subsequently sexually assaulted and killed the toddler. The age of criminal responsibility in England remains 10 years of age. Both Jon Venables and Robert Thompson were convicted of murder and sentenced originally to a minimum 10 years in custody.

While there are few children who commit such extremely violent acts, these notorious cases exemplify several of the key themes in this article. The above cases obviously involve the minimum jurisdictional age of juvenile and adult criminal courts, yet other contentious legal themes are also intrinsically embedded in justifying these minimums. Clearly, the initial concern is at what age children and adolescents must be considered to have the necessary cognitive, emotional and moral capacities to understand legal rights and wrongs. A related concern is at what age children and adolescents fully meet the legal criteria requiring a minimal understanding of the consequences of their criminal acts. Incidentally, most criminal courts require the accused to be competent to stand trial in which involves that they must be capable of understanding points of law and procedure and giving instructions to their defense council. Criminal sentencing usually involves varying levels of proportionately punitive and deterrent sentencing. The latter typically requires a consideration of aggravating and mitigating circumstances involving individual characteristics of the offender and the victim(s), as well as situational characteristics (e.g., was the act self-defense? Was the defendant intoxicated at the time of the crime). These considerations too have potentially definitive age parameters. For example, is a convicted 15-year-old offender that is clinically diagnosed as having suffered extreme trauma entitled to considerably more lenient mitigating assessment by the court than a 30-year-old adult that is clinically diagnosed with similar trauma, all other considerations being equal?

Corrado et al., Serious and Violent Young Offenders and Youth Criminal Justice: A Canadian Perspective. (Simon Fraser University Press, forthcoming in 2014).

CBC News (2013, September 3). Child under 12 acted alone in beating death of boy, 6, RCMP say. Retrieved from: http://www.cbc.ca/news/canada/saskatchewan/child-under-12-acted-alone-inbeating-death-of-boy-6-rcmp-say-1.1400513 (last visited February 13, 2014). 
This theme is particularly important in most national jurisdictions since the controversy around juvenile justice and its reform frequently has been focused on responding to serious and violent young offenders. Whether the debates are about lowering or not the minimum age of criminal responsibility, or revising the minimum age for automatic referral to adult criminal courts, there is a common underlying controversy that highlights two competing perspectives. The common theme is how to employ the two criminal justice systems in a complementary manner to most effectively protect society from serious and violent children, adolescents, and young adults. One view, mentioned above, is that such offenders deserve a punishment proportionate to the seriousness of their current offence plus a consideration of prior convictions as aggregating factors to determine custodial sentence length. In contrast, there is the view that the use of long custodial sentences simply amplifies the risk for serious and violent recidivism. Proponents of this second view purport instead that the sentencing emphasis should be on providing program services primarily in non-custodial settings. When the offence involved extreme violence, however, these services should only be initially available in non-punitive settings for short periods.

The minimum age of criminal responsibility varies substantially across Western country justice jurisdictions with England and Wales representing one of the lowest ages (i.e., 10 years) and Norway with one of the highest at 15 years of age. ${ }^{3}$ The maximum age of the juvenile justice system also vary substantially. Most juvenile justice jurisdictions have a 17-year age limit (e.g., Canada, United States, England and Wales), in which defendants who are 18 years or over are tried in standard adult courts. In contrast, Finland, Norway, and Sweden have set the maximum age at 21 years. The Nordic countries are an exception, however, with juvenile courts having jurisdiction for defendants between 15 years and 21 years of age. In contrast, several US states such as Indiana, Kansas, Vermont, and Wisconsin allow, but do not require, that a child as young as 10 years of age be tried in adult criminal courts for the charge of murder. ${ }^{4}$ In addition, while capital punishment has been held to be unconstitutional by the US Supreme court for youth under 16 years of age, ${ }^{5}$ capital punishment has not been prohibited for older adolescents aged 16 and 17 years. ${ }^{6}$

A central theme of this article is that these varying minimum and maximum age limits for juvenile justice jurisdiction are largely arbitrary and based on assumptions rather than systematic or scientific research. In addition, this article will also discuss current

3 Storgaard, Juvenile justice in Scandinavia, 5(2) Journal of Scandinavian Studies in Criminology and Crime Prevention (2004), pp. 188-204.

$4 \quad$ Feld and Bishop, Transfer of juveniles to criminal court, in The Oxford handbook of juvenile crime and juvenile justice eds. Feld and Bishop, (Oxford University Press, 2012), pp. 801-842.

$5 \quad$ Thompson v. Oklahoma, 487 U.S. 815 (1998).

$6 \quad$ Stanford v. Kentucky, 492 U.S. 361 (1989). 
research concerning competency-related abilities (e.g., in the United States, competency to waive Miranda rights and competency to stand trial) and sentence proportionality/ type of reprimand. While much of the recent 'breakthrough' research involving genetics, epigenetics and brain scan technologies concerning child/adolescent/young adult decision-making capacities remains necessarily tentative, there is sufficient research to begin examining several of the key assumptions in juvenile justice laws in countries such as Norway, Canada, and the United States. In initiating this empirically based discussion, we hope to provide information and analysis for those national jurisdictions where public and political debates too often appear to be influenced by media simplifications of inherently complex legal or scientific issues. This article consists of two parts. Part I summarizes the psychological and neurological empirical research on decision-making within the typical adolescent. Part II provides a discussion of the characteristics associated with the atypical adolescent (i.e., the serious violent young offender) and how their characteristics may interfere with an already underdeveloped adolescent decision-making system, therefore heightening risk-taking behavior.

\section{Decision-making and the development of responsible judgment in the typical adolescent}

\subsection{The role of cognitive abilities in decision-making}

Much of the research on human decision-making in the last part of the $20^{\text {th }}$ century focused primarily on cognitive domain indicators. Cognitive decision-making includes inductive reasoning (i.e., hypothesizing potential outcomes based on the available evidence), deductive reasoning (i.e., deriving conclusions based on logic), and identifying the risks and benefits of a given behavior. A long-standing consensus is that, by middle adolescence, approximately 16 years of age, cognitive capacity for decision-making does not differ from adults (i.e., 18 years of age and older). Conversely, youth under the age of 16 have significantly poorer cognitive decision-making capabilities when compared to adolescents 16 years of age and older. ${ }^{7}$

Likewise, research examining competency-related legal issues amongst adolescents, which is based on cognitive decision-making skills, reveals similar trends. For example, preteens (i.e., under 13 years of age) typically fail to meet the Dusky v. United

\footnotetext{
Ambuel and Rappaport, Developmental trends in adolescents' psychological and legal competence to consent to abortion, 16(2) Law and Human Behavior (1992), pp. 129-154; Belter and Grisso, Children's recognition of rights violations in counseling, Professional Psychology: 15(6) Research and Practice (1984), pp. 899-910; Garrison, Children's competence to participate in divorce custody decision-making, 20 Journal of Clinical Child Psychology (1991), pp. 78-87.
} 
States $(1960)^{8}$ standard for competency to stand trial, ${ }^{9}$ and demonstrate less knowledge of legal and trial-related concepts compared to late adolescents ${ }^{10}$ and adults. ${ }^{11}$ More importantly, earlier research indicates that preteen psycho-legal competency domains are comparable to those of adults with mental retardation. ${ }^{12}$ Early adolescents (13-15 years) show improvements, but still demonstrate poorer abilities on key competency-related domains than late adolescents (16-17 years) $)^{13}$ and adults (18+ years).$^{14}$ Developmental differences in competency-related abilities do, however, remain stable from 17 years of age. ${ }^{15}$

In research literature based only on the cognitive domain (i.e., excluding the psychosocial domain), late adolescents appear just as cognizant as adults of the risks they take and as capable of making decisions outside of the courtroom, as well as within. This consistent finding from one particular domain of decision-making, however, contradicts a central legal presumption of several Western legal systems (e.g., Australia, Canada, and United Kingdom), that youth generally are less capable of rational and logical decision-making strategies than adults. In contrast, research from the psychosocial domain ${ }^{16}$ of decision-making supports this assumption. Most importantly, a large body of empirical research indicates that risk-taking behavior, including serious criminality, peaks

8 Dusky v. United Sates 362 U.S. 402 (1960). This United States Supreme Court case set the minimum criteria for competency to stand trial. Specifically, to be competent, the defendant must possess an adequate factual understanding (e.g., understand the roles of the members of the criminal justice system), rational understanding (e.g., appreciation of the potential negative consequences associated with a guilty decision), and the ability to communicate with counsel. Importantly, three underlying psycho-legal principles are relevant to decisions of competency: understanding, reasoning, and appreciation, see Poythress et al., The MacArthur Competence Assessment Tool - Criminal Adjudication: Professional Manual (Psychological Assessment Resources 1999.

9 McKee, Competency to stand trial in preadjudicatory juveniles and adults, $26 \mathrm{~J}$. Am. Acad. Psychiatry Law (1998), pp. 89-99.

10 Peterson-Badali et al., Young children's legal knowledge and reasoning ability, 39 Canadian Journal of Criminology (1997), pp. 145-170.

11 Grisso, Juveniles' waiver of rights: Legal and psychological competence (Plenum Press 1981)

12 Fulero and Everington, Assessing competency to waive Miranda rights in defendants with mental retardation, 19(5) Law and Human Behavior (1995), pp. 533-543.

13 Grisso et al., Juveniles' competence to stand trial: A comparison of adolescents' and adults' capacities as trial defendants, 27(4) Law and Human Behavior (2003), pp. 333-363; Savitsky and Karras, Competency to stand trial among adolescents, 19(74) Adolescence (1984), pp. 349-358.

14 Supra, note 15, Grisso et al 2003.

15 Supra, note 15, Grisso et al $2003 \mathrm{ff}$.

16 This domain of research, generally, is concerned with the role of social factors (e.g., peer influence, situational context) and psychological factors (e.g., self-control) on decision-making. 
during mid-adolescence and rapidly declines in late adolescence and early adulthood. ${ }^{17}$ Specifically, youth in the early and middle adolescent stages are most likely to abuse substances, engage in delinquent or criminal behavior, drive recklessly, and participate in unsafe sexual practices. ${ }^{18}$

Unsurprisingly, beginning in the mid-1990s, criticisms of the single cognitive domain approach emerged. ${ }^{19}$ The main concern with rational choice based cognitive decision-making models was that they are inappropriately focused on economic principles involving the use of logical inductive and deductive reasoning. Instead, an alternative mode ${ }^{20}$ was suggested, which asserts that responsible decision-making resulting in reduced risk-taking is a product of two interrelated factors: the above-mentioned cognitive capacities as well as psychosocial abilities. ${ }^{21}$ Critically, while cognitive abilities may be fully developed, on average, by mid-adolescence, psychosocial abilities continue to develop throughout adolescence and even into the early adult years. In effect, age-based psychosocial deficits are constraints in the utilization of key cognitive skills associated with avoiding risk-taking and potentially both self-harming and victimizing behavior such as serious criminality.

17 Arnett, Reckless behavior in adolescence: A developmental perspective, 12 Developmental Review (1992), pp. 339-373; Donovan et al., Syndrome of problem behavior in adolescence: A replication, 56:5 Journal of Consulting and Clinical Psychology (1988), pp. 762-765; Gottfredson and Hirschi, A general theory of crime (Stanford University Press 1990); Gullone et al., The adolescent risk-taking questionnaire: Development and psychometric evaluation, (15:2) Journal of Adolescent Research (2000), pp. 231-250.

18 Centers for Disease Control and Prevention, Youth risk behavior surveillance - United States, 2005, 55(SS5) Morbidity \& Mortality Weekly Report (2006), pp. 1-108; Moffitt, Adolescencelimited and life-course-persistent antisocial behavior: A developmental taxonomy, 100(4) Psychological Review (1993), pp. 674-701; Reyna and Farley, Risk and rationality in adolescent decision-making: Implications for theory, practice, and public policy, 7 Psychological Science (2006), pp. 1-44.

19 Cauffman and Steinberg, The cognitive and affective influences on adolescent decision-making, 68(4) Temple Law Review (1995), pp. 1765-1790.

20 Scott et al., Evaluating adolescent decision making in legal context, 19(3) Law and Human Behavior (1995), pp. 221-244.

$21 \quad$ While Cauffman and Steinberg (see Supra, note 20) refer to psychosocial abilities as encompassing three key components (i.e., responsibility, perspective, and temperance), we refer to psychosocial abilities more broadly in terms of an individual's psychological, emotional and social capacity, outside of cognitive functioning. 
Figure 1. Decision-making tree

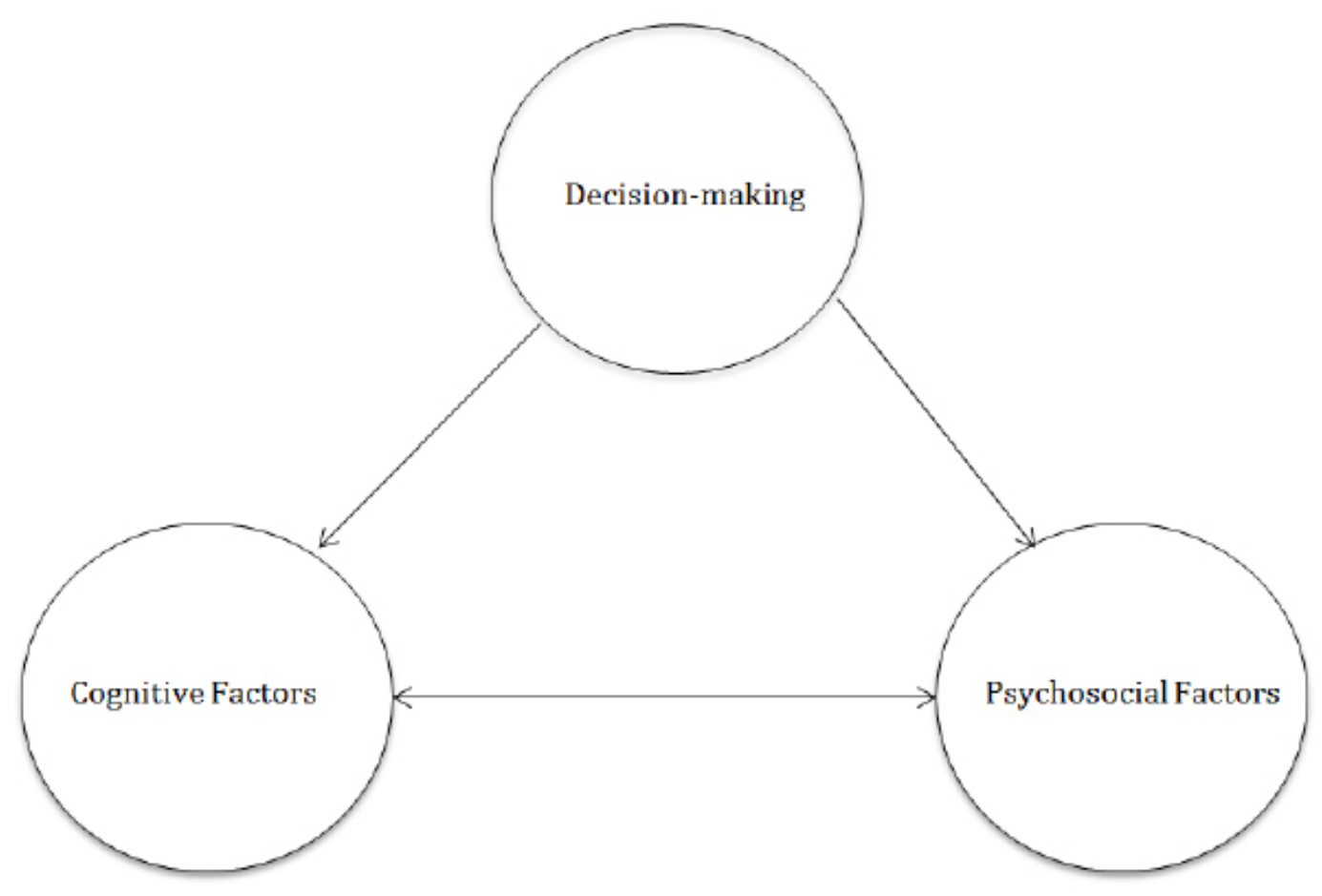

$\underline{\text { Cognitive Factors }}$

1. Inductive Reasoning:

- Hypothesizing potential outcomes based on available evidence

2. Deductive reasoning:

- Deriving conclusions based on logic

3. Identification of risks and benefits of a behavior

\section{Psychosocial Factors}

1. Individual Domain

- Sensitivity to reward

- Sensitivity to punishment

- Emotion regulation

- Self-control

2. Contextual/situational Domain

- Novelty of situation

- Ambiguity of situation

- Peer group 


\subsection{The role of psychosocial abilities in adolescent decision-making}

For some adolescents and, to a lesser extent, young adults, several risk factors have been identified, including hypersensitivity to rewards and hyper-insensitivity to the costs of risky behaviors generally and criminal acts, specifically. ${ }^{22}$ By overemphasizing the possible rewards of a risky decision and simultaneously downplaying the potential negative consequences, ${ }^{23}$ adolescents, not uncommonly, exhibit a reduced ability to effectively plan alternative and less risky methods to obtain desired goals. ${ }^{24}$ Adolescents also are more likely to have a "tunnel vision" decision-making style based on immediate gratification (e.g., sexual pleasure), while ignoring potential long-term negative implications (e.g., unexpected pregnancy). Often crime contexts or situations (e.g., drug dealing, sexual assault) provide a means for immediate gratification of a given need (e.g., money, sexual gratification). Again, this psychosocial pattern peaks between mid-adolescence and early adulthood (i.e., 14-21 years of age) ${ }^{25}$

In addition, certain decision-making contexts such as ambiguous, new, or stressful situations, affect adolescents' ability to effectively utilize their cognitive decision-making capacities. ${ }^{26}$ More specifically, adolescents are more likely to make irresponsible risky decisions in emotionally heightened contexts than adults. ${ }^{27}$ These contexts frequently are exacerbated by extreme emotional moods, which are typical of the adolescent develop-

22 Blakemore and Robbins, Decision-making in the adolescent brain, 15(9) Nature Neuroscience (2012), pp. 1184-1191; Galvan et al., Earlier development of the accumbens relative to orbitofrontal cortex might underlie risk-taking behavior in adolescents, 2625 Journal of Neuroscience (2006), pp. 6885-6892; Galvan et al., Risk-taking and the adolescent brain: Who is at risk? 10(2) Developmental Science (2007), pp. F8-F14; Steinberg et al., Age differences in sensation seeking and impulsivity as indexed by behavior and self-report: Evidence for a dual systems model, 44(6) Developmental Psychology (2008), pp. 1764-1778.

23 Benthin et al., A psychometric study of adolescent risk perception, 16(2) Journal of adolescence (1993), pp. 153-168; Gardner and Herman, Adolescents' AIDS risk taking: A rational choice perspective, 50 New Directions for Child and Adolescent Development (1990), pp. 17-34.

24 Greene, Future-time perspective in adolescence: The present of things future revised, 15 Journal of Youth and Adolescence (1986), pp. 99-111.

25 See Cauffman et al., Age differences in affective decision making as indexed by performance on the Iowa Gambling Task, 46 Developmental Psychology (2010), pp. 193-207.

$26 \quad$ See Supra notes 20 and 21.

27 Casey et al., The adolescent brain, 1124 Ann. NY Acad. Sci (2008), pp. 111-126; Somerville et al., A time of change: Behavioral and neural correlates of adolescent sensitivity to appetitive and aversive environmental cues, 72 Brain and Cognition (2010), pp. 124-133; Somerville et al., Frontostriatal maturation predicts cognitive control failure to appetitive cues in adolescents, 23(9) Journal of Cognitive Neuroscience (2011), pp. 2123-2134. 
mental stage. ${ }^{28}$ Under such situational pressures, adolescents are less likely than adults to make use of all available information and rely instead on partial information and simple heuristics to make decisions, particularly within contexts involving antisocial behavior (e.g., "If I don't steal like my friends then they will think I'm a loser"). In other words, adults exhibit greater emotional stability in their decision-making across similar challenging situations and contexts.

Further, antisocial peer influence confounds the negative impact of situational influences on adolescent risky decision-making. Adolescents are most influenced by their peers than during any other developmental stage, especially in risk behaviors involving a peer group ${ }^{29}$ including criminality. ${ }^{30}$ Peer influence exhibits a curvilinear relationship with age: it increases through early adolescence, peaks in middle adolescence ( $\sim 15$ years) and slowly declines into adulthood. ${ }^{31}$ Importantly, while adults overwhelmingly commit the majority of crimes in most countries, most crimes committed by adolescents, including serious and violent crimes (e.g., aggravated assault, homicide) involve other adolescents; in contrast, adults typically are lone offenders. ${ }^{32}$

Finally, adolescents have, on average, lower levels of self-control than adults. ${ }^{33}$ Not surprisingly, a dominant theory of crime has been based on the low self-control construct, defined essentially as impulsivity and lack of effortful control in all forms of decision-making. ${ }^{34}$ More specifically, self-control refers to the ability to modulate or exercise

28 Buchanan et al., Are adolescents the victims of raging hormones? Evidence for activational effects of hormones on moods and behavior at adolescence, 111 Psychological Bulletin (1992), pp. 62-107.

29 Supra, note 23, Blakemore and Robbins 2012 ff.; Gardner and Steinberg, Peer influence on risk taking, risk preference, and risky decision making in adolescence and adulthood: An experimental study, 41(4) Developmental Psychology (2005), pp. 625-635; Steinberg and Monahan, Age differences in resistance to peer influence, 43(6) Developmental Psychology (2007), pp. 1531-1543; Simons-Morton and Farhat, Recent findings on peer group influences on adolescent substance use, 31(4) Journal of Primary Prevention (2010), pp. 191-208.

30 Carrington, Co-offending and the development of the delinquent career, 47(4) Criminology (2009), pp. 1295-1329.

31 Berndt, Developmental changes in conformity to peers and parents, 15(6) Developmental Psychology (1979), pp. 608-616; Costanzo and Shaw, Conformity as a function of age level, 37(4) Child Development (1966), pp. 967-975; Supra, note 30, Gardner and Steinberg 2005 ff.

32 Farrington, Early predictors of adolescent aggression and adult violence, 4(2) Violence and victims (1989), pp. 79-100; Lipsey and Derzon, Predictors of violent or serious delinquency in adolescence and early adulthood: A synthesis of longitudinal research, in Serious \& Violent juvenile Offenders: Risk factors and successful interventions, eds. Loeber and Farrington (Sage Publications 1998), pp. 86-105; Supra, note 19, Moffitt 1993 ff.; Saner and Ellickson, Concurrent risk factors for adolescent violence,19(2) Journal of Adolescent Health (1996), pp. 94-103.

33 Supra, note 24, Blakemore and Robbins 2012 ff.; Leon-Carrion et al., Development of the inhibitory component of the executive functions in children and adolescence, 114 International Journal of. Neuroscience (2004), pp. 1291-1311; Supra, note 24. Steinberg et al $2008 \mathrm{ff}$.

$34 \quad$ Supra, note 18, Gottfredson and Hirschi $1990 \mathrm{ff.}$ 
constraint over one's immediate attentional, emotional, and behavioral impulses. Low self-control can intensify the typically reward-centered focus of adolescents, thereby further diminishing their cost-assessment of antisocial and self-harming risky behaviors. ${ }^{35}$ Low self-control is one of the most robust correlations to serious delinquent and criminal behavior. ${ }^{36}$ Yet, most importantly, despite the general decline of criminal behavior in late adolescence and early adulthood, low self-control generally does not diminish more fully until approximately the mid-20s. ${ }^{37}$ The explanation for this turning point at adulthood regarding low self-control primarily has involved more recent research on brain neuronal maturation. Collectively, psychosocial factors include both individual (e.g., low self-control; hyperfocus on rewards; hypofocus on the risks and long-term implications) and situational/contextual factors, such as peer influence, as well as highly emotional situations which are particularly new, novel, and/or ambiguous.

35 Farrington, Experiments on deviance with special reference to dishonesty, In Advances in experimental social psychology, vol 12, ed, Berkowitz (Academic Press 1988), pp. 207-252; Farrington et al., The development of offending from age 8 to age 50: Recent results from the Cambridge Study in Delinquent Development, 92 Monatsschrift fur Kriminologie und Strafrechtsreform (2009), pp. 160-173; Farrington et al., Long-term criminal outcomes of hyperactivity-impulsivity-attention-deficit and conduct problems in childhood, In Straight and devious pathways from childhood to adulthood (Eds, Robins and Rutter) (Cambridge University Press 1990), pp. 62-82; Caspi and Silva, Temperamental qualities at age three predict personality traits in young adulthood: Longitudinal evidence from a birth cohort, 66(2) Child Development (1995), pp. 486-498; White et al., Measuring impulsivity and examining its relationship to delinquency, 103(2) Journal of Abnormal Psychology (1994), pp. 192-205; Supra, note 18, Gottfredson and Hirschi $1990 \mathrm{ff}$.

36 Pratt and Cullen, The empirical status of Gottfredson and Hirschi's general theory of crime: A meta-analysis, 38(3) Criminology (2000), pp. 931-964.

37 Steinberg, A social neuroscience perspective on adolescent risk-taking, 28 Developmental Review (2008), pp. 78-106. 


\subsection{Neurological development of decision-making and the adolescent brain $^{38}$}

The adolescent brain typically undergoes several normative cognitive and psychosocial developmental changes in decision-making abilities. ${ }^{39}$ These changes are initially linked to physical maturation associated with puberty-related hormones such as testosterone, ${ }^{40}$ as well as other hormones such as cortisol ${ }^{41}$ and neurotransmitters ${ }^{42}$ such as epinephrine (adrenaline). ${ }^{43}$ These neurotransmitter and hormonal changes (discussed in more detail below) are associated with changes in $\operatorname{mood}^{44}$ and are influenced by an interaction between rapidly evolving gender-based self-identities and stressful social relationships, especially those involving authority figures and peers. Self-identity labeling usually

38 See appendix A for a list of key terms and definitions

39 Paus, Mapping brain maturation and cognitive development during adolescence, 9(2) Trends in Cognitive Sciences (2005), pp. 60-68; Steinberg, Adolescent development and juvenile justice, 5 Annual Review of Clinical Psychology (2009), pp. 459-485; Blakemore, Development of the social brain in adolescence, 61 The Quarterly Journal of Experimental Psychology (2012), pp. 40-49; Pfeifer and Blakemore, Adolescent social cognitive and affective neuroscience: Past, present, and future, 7 Social Cognitive \& Affective Neuroscience (2012), pp. 1-10; Blakemore, Imaging brain development: The adolescent brain, 61 NeuroImage (2012), pp. 397-406; Blakemore and Coudhury, Development of the adolescent brain: Implications for executive function and social cognition, 47(3) Journal of Child Psychology and Psychiatry (2006), pp. 296-312; Blakemore and Robbins, Decision-making in the adolescent brain, 15(9) Nature Neuroscience (2012), pp. 11841191.

40 Dabbs et al., Salivary testosterone and cortisol among late adolescent male offenders, 19(4) Journal of Abnormal Child Psychology (1991), pp. 469-478; Daitzman and Zuckerman, Disinhibitory sensation seeking, personality and gonadal hormones, 1(2) Personality \& Individual Differences (1980), pp. 103-110.

${ }^{41}$ Oosterlaan et al., Low basal salivary cortisol is associated with teacher-reported symptoms of conduct disorder, 134 Psychiatry Research (2005), pp. 1-10; Shoal et al., Salivary cortisol, personality, and aggressive behavior in adolescent boys: A 5-year longitudinal study, 42(9) Child and Adolescent Psychiatry and Mental Health, (2003), pp. 1101-1107.

42 Neurotransmitters are chemicals within the nervous system that are responsible for the transmission of information from one cell to another. Accordingly, they are critical to healthy functioning, including, but not limited to, domains such as decision-making, emotional regulation, and movement.

43 Curtin et al., Reward dependence is positively related to urinary monoamines in normal men, 42(4) Biological Psychiatry (1997), pp. 275-281; Peskin et al., Personal characteristics of delinquents: Neurobiology, genetic predispositions, individual psychosocial attributes, in The Oxford handbook of juvenile crime and juvenile justice, eds. Feld and Bishop (Oxford University Press 2012), pp. 73-106; Swaab, We are our brains: A neurobiography of the brain, from the womb to Alzheimer's (Spiegel \& Grau 2014).

44 Bao et al., Neurotransmitters and neuropeptides in depression, In Handbook of Clinical Neurology, eds. Schlaepfer and Nemeroff, $3^{\text {rd }}$ ed., (Elsevier 2012) pp. 107-136; Raadsher et al., Increased numbers of corticotropin-releasing hormone expressing neurons in the hypothalamic paraventricular nucleus of depressed patients, 60 Neuroendocrinology (1994), pp. 436-444. 
involves a combination of the influences of both external parental/authority-invoked labels and peer-invoked labels. ${ }^{45}$ Differences or gaps between desirable self-identities and negative, externally imposed labels, can, not uncommonly, act as a major source of adolescent stress, frustration, and anger. These negative emotional reactions can increase the likelihood of anxiety or depression, ${ }^{46}$ as well as aggression. ${ }^{47}$

Certain combinations of unusual neurological and hormonal profiles consistent with early and persistent risk-taking and anti-social behavior also have been associated with child and adolescent developmental disorders, most importantly, oppositional defiant disorder (ODD) ${ }^{48}$ conduct disorder (CD) ${ }^{49}$ as well as developmental neurological disorders such as Fetal Alcohol Spectral Disorder (FASD) $)^{50}$ and autism spectrum disorder (ASD).$^{51}$ Further, reduced levels of cortisol combined with high levels of testosterone are associated with juvenile delinquency. ${ }^{52}$ Different neurological and hormonal profiles are also evident for adult personality disorders, particularly, antisocial personality disorder $(\mathrm{ASPD})^{53}$ and the related and more serious, psychopathic personality disorder (PPD). ${ }^{54}$

45 Hay and Ashman, The development of adolescents' emotional stability and general self-concept: The interplay of parents, peers, and gender, 50 International Journal of Disability, Development, and Education (2003), pp. 77-91.

46 Boldero et al., Self-discrepancies and negative affect: A primer on when to look for specificity, and how to find it, 57(3) Australian Journal of Psychology (2005), pp. 139-147; De Vries et al., Autism spectrum disorders in gender dysphoric children and adolescents, 40(8) Journal of Autism and Developmental Disorders (2010), pp. 930-936.

47 Peled and Moretti, Rumination on anger and sadness in adolescence: Fueling of fury and deepening of despair, 36 Journal of Clinical Child and Adolescent Psychology (2007), pp. 66-75.

48 Van Goozen et al., Increased adrenal androgen functioning in children with oppositional defiant disorder: A comparison with psychiatric and normal controls, 39(11) Journal of the American Academy of Child \& Adolescent Psychiatry (2000), pp. 1446-1451.

$49 \quad$ Supra, note 41, Oosterlaan et al. $2005 \mathrm{ff}$.

$50 \quad$ Supra, note 42. Peskin et al. $2012 \mathrm{ff}$.

51 Minshew and Keller, The nature of brain dysfunction in Autism: Functional brain imaging studies, 23(2) Current opinion in neurology (2010), pp. 124-130.

52 Popma et al., Cortisol moderates the relationship between testosterone and aggression in delinquent male adolescents, 61(3) Biological Psychiatry (2007), pp. 405-411.

53 Raine et al., Reduced prefontral gray matter volume and reduced autonomic activity in antisocial personality disorder, 57(4) Archives of general psychiatry (2000), pp. 119-127.

54 De Oliveira-Souza et al., Psychopathy as a disorder of the moral brain: Fronto-temporo-limbic grey matter reductions demonstrated by voxel-based morphometry, 40(3) NeuroImage (2008), pp. 1202-1213. 
Both $\mathrm{ASPD}^{55}$ and $\mathrm{PPD}^{56}$ are believed to have their roots in earlier development. A contentious clinical issue that often has forensic and legal relevance, though, is whether later adult personality disorders can be assessed in the earlier adolescent stages or even possibly in late childhood. ${ }^{57}$ The legal issues often focus on rational decision-making as opposed to less "controllable" decision-making based on impulse, which was discussed above regarding competency to stand trial, criminal culpability and the mitigation or aggravation of sentencing.

A related research theme that is currently emerging involves brain morphology (i.e., structure/shape) and its development from childhood to adulthood. This change in brain morphology across early developmental periods has important implications, to be discussed below, for cognitive and psychosocial decision-making. In particular, children and adolescence experience pronounced neurological development and it is not until adulthood that the brain becomes fully developed. Tomáš Paus ${ }^{58}$ and Laurence Steinberg $^{59}$ identified several interrelated structural changes of critical importance in the adolescent brain. Importantly, during pre- and early-adolescence, a substantial reduction in grey matter ${ }^{60}$ occurs within the prefrontal cortex (i.e., the central brain structure for decision-making located at the front of the brain), which is especially important for prosocial

55 Lahey et al., Predicting future antisocial personality disorder in males from a clinical assessment in childhood, 73(3) Journal of Consulting and Clinical Psychology (2005), pp. 389-399.

56 Pardini et al., Callous/unemotional traits and social-cognitive processes in adjudicated youths, 42(3) Journal of the American Academy of Child and adolescent Psychiatry (2003), pp. 364-371; Lynman, Early identification of chronic offenders: Who is the fledgling psychopath?, 120(3) Psychological Bulletin (1996), pp. 209-234.

57 Corrado, Does psychopathy appear only in adulthood?, in The Future of Criminology, eds. Loeber and Welsch (Oxford University Press 2012) pp. 141-152; Corrado et al., Predictive validity of the Psychopathy checklist: Youth Version: Psychopathic symptoms and recidivism, 22 Behavioral Science and the Law (2004), pp. 5-22; Salekin and Lynam, Handbook of Child \& Adolescent Psychopathy (The Guilford Press 2010); Vincent and Hart, Psychopathy in childhood and adolescence: Implications for the assessment and management of multi-problem youths, in Multi-problem violent youth: A foundation for comparative research on needs, interventions, and outcomes, eds. Corrado et al. (Amsterdam IOS Press 2002), pp. 150-163.

58 Supra, note 39, Paus $2005 \mathrm{ff}$.

$59 \quad$ Supra, note 38.

60 Grey matter is an unmyelinated of neuron (i.e., brain cell) within the nervous system. Grey matter can be contrasted with a second prominent neuron within the nervous system referred to as white matter (i.e., glia). White matter contains a myelinated axon (i.e., an axon is a projection from the cell body and is responsible for the transmission of cell signals), in which the myelination acts as an insulator around the cell axon; therefore accelerating the transmission of the message from one neuron to the next. Accordingly, white matter more efficiently communicates messages between neurons than does grey matter given that grey matter lacks the insulated (i.e. myelin) covering. 
behaviors. ${ }^{61}$ Grey matter reduction involves synaptic pruning, ${ }^{62}$ which peaks at approximately 16 years of age, ${ }^{63}$ then slowly reduces into early adulthood, and is largely complete by 25 or 26 years of age. ${ }^{64}$ Synaptic pruning is hypothesized to be essential for the efficiency or 'fine-tuning' of pathways within the brain and the emergence of "mature" patterns of neural processing that have a positive effect on decision-making (i.e., reduction of harmful high-risk behaviors). Both the cognitive and psychological domains of decision-making appear to be enhanced by two specific factors. ${ }^{65}$ These are, on the one hand, the efficiency of cortical ${ }^{66}$ neuronal networks in the various regions of the prefrontal cortex, and on the other hand the complex interconnections between the prefrontal cortex and the emotional regions of the brain, particularly the limbic areas. ${ }^{67}$ The initial acceleration in the rate of grey matter reduction during early adolescence corresponds with improvements in basic cognitive decision-making mentioned above. This pattern suggests that this genetically-determined brain development (i.e., pruning) is likely critical to adolescent receptivity to environmental factors (e.g., social discipline, peer pressure) that strengthen the use of the psychosocial domain to reduce impulsive high-risk life-styles. Conversely, any disruptions in this pruning process, or, more broadly, the neurodevelopmental processes preceding pruning, is likely to diminish this influence. These disruptions may be caused by rare genetic mutations, such as the case with autism spectrum disorder, ${ }^{68}$ epigenetic effects (e.g., severe stress ${ }^{69}$, excessive/binge alcohol

The prefrontal cortex is responsible for executive functions such as problem solving, selfregulation, planning, working memory, reasoning, and attention, among others. As such, the prefrontal cortex plays a key role in decision-making and risk taking.

62 Synaptic pruning refers to the removal of synapses (synapses are located at the end of axons and are responsible for the release of chemical messengers (i.e., neurotransmitters) to stimulate adjacent neurons).

63 Casey et al., Imaging the developing brain: What have we learned about cognitive development? 9(3) Trends in Cognitive Science (2005), pp. 104-110.

64 Raznahan et al., Patterns of coordinated anatomical change in human cortical development: A longitudinal neuroimaging study of maturational coupling, 72(5) Neuron (2011), pp. 873-884.

65 Giedd et al., Brain development during childhood and adolescence: A longitudinal MRI study, 2(10) Nature neuroscience (1999), pp. 861-863; Zehr et al., Dendritic pruning of the medial amygdala during pubertal development of the male Syrian hamster, 66(6) Journal of Neurobiology (2006), pp. 578-590.

${ }_{66}$ Refers to the cerebral cortex of the brain, which is the thin outer neuronal layer of the brain responsible for higher order processes such as thought, attention, memory, consciousness, and language, among others.

67 The limbic system is located in the middle of the brain (under the cerebral cortex) and consists of multiple brain structures (e.g., amygdala, hippocampus, limbic cortex, limbic midbrain), which are heavily involved in emotion among other processes (e.g., memory).

68 Abrahams and Geschwind, Advances in autism genetics: On the threshold of a new neurobiology, 9(5) Nature Reviews Genetics (2008), pp. 341-355.

69 Charil et al., Prenatal stress and brain development, 65 Brain Research Reviews (2010), pp. 56-79. 
consumption by pregnant mother ${ }^{70}$ ), adolescent substance use (e.g., marijuana ${ }^{71}$ during this adolescent period), as well as early childhood emotional trauma, ${ }^{72}$ early childhood stress, ${ }^{73}$ as well as physical brain injury, ${ }^{74}$ among others.

Paus $^{75}$ and Steinberg ${ }^{76}$ also elaborated a second major neurological development: the increase in white matter (i.e., glia) within the prefrontal cortex. Given the essential role of the prefrontal cortex in executive functions such as decision-making, attention, planning, and self-control, this increase in white matter has been hypothesized to be associated with the significant improvements in decision-making capabilities observed in the late adolescent stage. Especially affected is the integration of cognitive and psychosocial domains that enhance the ability to reason more effectively, to consider and plan for the future, as well as increased self-regulation. ${ }^{77}$ This white matter increase appears to culminate at approximately 21 years. ${ }^{78}$

The third neurological change in adolescence, initially discussed above with regard to self-identity, involves dopamine ${ }^{79}$ activity within the limbic system. The limbic system is responsible for emotional and social processing associated with social judgment and reasoning. Importantly, the limbic system affects reward and sensation-seeking behavior. Again, during the immediate pre-pubescence and puberty stages, a dramatic increase in dopamine activity occurs within the limbic system that stimulates reward and sensation-seeking behaviors beginning in early adolescence. ${ }^{80}$ Importantly, this surge in do-

70 Guerri and Pascual, Mechanisms involved in the neurotoxic, cognitive, and neurobehavioral effects of alcohol consumption during adolescence, 44 Alcohol (2010), pp. 15-26.

71 Bonnin et al., Effects of perinatal exposure to $\Delta^{9}$-tetrahydrocannabinol on the fetal and early postnatal development of tyrosine hydroxylase-containing neurons in rat brain, 7 Journal of Molecular Neuroscience (1996), pp. 291-308; Malone et al., Adolescent cannabis use and psychosis: Epidemiology and neurodevelopmental models, 160(3) British Journal of Pharmacology (2010), pp. 511-522.

72 Perry et al., Childhood trauma, the neurobiology of adaptation, and 'use-dependent' development of the Brain: How 'states' become “traits', 16(4) Infant Mental Health Journal (1995), pp. 271-291.

73 Teicher et al., The neurobiological consequences of early stress and childhood maltreatment, 27 Neuroscience and Biobehavioral Reviews (2003), pp. 33-44.

74 Taylor and Alden, Age-related differences in outcomes following childhood brain insults: An introduction and overview, 3(6) Journal of the International Neuropsychological Society (2000), pp. 555-567.

75 Supra, note 39.

76 Supra, note 38.

77 Luna et al., Maturation of widely distributed brain function subserves cognitive development, 13(5) Neuroimage (2001), pp. 786-793.

78 Lenroot et al., Sexual dimorphism of brain developmental trajectories during childhood and adolescence, 36(4) Neuroimage (2007), pp. 1065-1073.

79 Dopamine is a neurotransmitter (i.e., chemical messenger in the brain) that has multiple pathways through different brain regions and has many important roles in the nervous system. Supra, note 38. 
pamine activity within the limbic network occurs long before the full maturation of the cognitive control system, which typically has an inhibitory effect.

A basic change in the secretion of the hormone oxytocin, associated with social bonding, is the fourth key neurological change in adolescence. ${ }^{81}$ This also facilitates an increased awareness of the opinion of others, which is essential for the development and maintenance of empathy and prosocial behaviors. ${ }^{82}$ Conversely, reduced empathy is associated with greater susceptibility to bullying, particularly violent forms of bullying, ${ }^{83}$ as well as serious violent crime more generally in adolescence. ${ }^{84}$

Obviously, it is not possible in this article to fully explore the enormously complex neuroscience of rational decision-making among children, adolescents and young adults. We instead have tried to highlight several of the more recent "breakthrough" findings that have, we believe, direct implications for juvenile justice. One of the most important limitations of this review was the very brief mention of the personality disorders that have increasingly become a major theoretical and politically contentious issue. For the few extremely violent young offenders, a popular public and political response in several countries such as Canada and certain US states has been to assume that punishment and deterrence is the necessary basis for sentencing. It is, however, not yet evident from current research whether a personality disorder-based perspective on serious and violent crime can be incorporated within such discussions on public policy in the field of youth justice. The following section seeks to elaborate on key characteristics associated with serious and violent young offenders, including the role of personality disorder, and their implication for decision-making.

\section{Serious violent young offenders: individual characteristics and decision-making}

Serious and violent young offenders (SVOs) represent a subgroup of juvenile delinquents who are responsible for the majority of serious crimes such as robbery, aggravated as-

81 Winslow and Insel, Neuroendocrine basis of social recognition, 14(2) Current Opinion in Neurobiology (2004), pp. 248-253.

$82 \quad$ Supra, note 38

83 Jolliffe and Farrington, Examining the relationship between low empathy and bullying, 32(6) Aggressive Behavior (2006), pp. 540-550.

${ }_{84}$ Frick et al., Callous-unemotional traits and conduct problems in the prediction of conduct problem severity, aggression, and self-report of delinquency, 31(4) Journal of Abnormal Child Psychology (2003), pp. 457-470. 
sault, drug trafficking, and sexual assault throughout the course of their life. ${ }^{85}$ SVOs typically suffer from cognitive deficits such as poor problem-solving skills, limited abstract reasoning abilities, ${ }^{86}$ as well as low verbal IQ. ${ }^{87}$ These cognitive deficits have direct negative consequences on the adolescent's ability to accurately and comprehensively assess the risks and benefits of a given situation, and, accordingly, to make mature responsible decisions.

A major long-term and on-going Canadian study of incarcerated young offenders indicates that young offenders from certain ethnic and racial groups, primarily Aboriginal, are substantially over represented among SVOs. ${ }^{88}$ Another major theme is the role of substance abuse among SVOs. For example, approximately $36 \%$ of youth incarcerated in this detention center consumed alcohol and/or marijuana prior to 12 years of age. Approximately $50 \%$ of the sample have used cocaine, $30 \%$ have used heroin, and $20 \%$ have consumed speed. ${ }^{89}$ The impact of serious substance abuse on brain development and functioning is well known, ${ }^{90}$ as is its subsequent negative impact on decision-making such as increased impulsivity and reward-seeking behavior. ${ }^{91}$ In a Dutch study of incarcerated young offenders, Coby Vreugdenhil and colleagues ${ }^{92}$ in 2004 reported the mental

85 Kelley et al., Epidemiology of serious violence. Office of Juvenile Justice Bulletin. Washington, D.C.: Office of Juvenile Justice and Delinquency Prevention, U.S. Department of Justice (1997); LeBlanc and Fréchette, Male criminal activity from childhood through youth: Multilevel and developmental perspectives (Springer-Verlag 1989); Supra, note 19, Moffitt 1993 ff.; Wolfgang et al., Evaluating criminology (Elsevier 1972).

86 Séguin et al., Cognitive and neuropsychological characteristics of physically aggressive boys, 104(4) Journal of Abnormal Psychology (1995), pp. 614-624.

87 Brennan et al., Integrating biological and social processes in relation to early-onset persistent aggression in boys and girls, 39(2) Developmental Psychology (2003), pp. 309-323. Lynman et al., Neuropsychological tests predict persistent male delinquency, 32(2) Criminology (1994), pp. 101-124; Raine, The psychopathology of crime: Criminal behavior as a clinical disorder (Academic Press 1993).

88 Corrado and Cohen, A needs profile of Aboriginal youth in prison, 14(3) FORUM on Corrections Research (2002), pp. 20-24; Corrado et al., The over-representation of Aboriginal youth in custody: Policy challenges, 10 Horizons (2008), pp. 79-82; Peters and Corrado, An examination of the early 'Strains' of imprisonment among young offenders incarcerated for serious crimes, 2(2) Journal of Juvenile Justice (2013), pp. 76-94.

89 McCuish and Corrado, A lifestyles theoretical perspective on patterns of substance use and offending profiles of juvenile offenders. Paper presented at the American Society of Criminology on November 15, 2012.

90 Guerri and Pascual, Mechanisms involved in the neurotoxic, cognitive, and neurobehavioral effects of alcohol consumptions during adolescence, 44 Alcohol (2010), pp.15-26.

${ }_{91}$ Jentsch and Taylor, Impulsivity resulting from frontostriatal dysfnction in drug abuse: Implications for the control of behavior by reward-related stimuli,146(4) Psychopharmacology (1999), pp. 373-390.

92 Vreugdenhil et al., Psychiatric disorders in a representative sample of incarcerated boys in The Netherlands, 43 Journal of the American Academy of Child \& Adolescent Psychiatry (2004), pp. 97-104. 
health risk profiles were extreme in their sample (i.e., 90\% reported at least one psychiatric disorder, with 75\% reporting disruptive behavior disorder, 55\% reporting substance use disorder, and 34\% reporting psychotic symptoms). These findings from the Dutch sample are consistent with samples from the United States in which approximately twothirds of incarcerated juvenile offenders have at least one psychiatric disorder, ${ }^{93}$ while a substantial minority exhibit moderate to high symptoms for more severe psychiatric disorders such as schizophrenia (30\%), mania (18\%), and posttraumatic stress disorder (26\%). ${ }^{94}$ Relatedly, psychopathic traits are more common in juvenile offenders following a chronic offending trajectory as compared to a more moderate rate of offending trajectory. ${ }^{95}$ Finally, SVOs are also characterized by early childhood trauma such as prenatal and perinatal exposure to toxins (e.g., alcohol, cocaine), ${ }^{96}$ physical and sexual childhood abuse, ${ }^{97}$ and are more likely to suffer from neurological deficits. ${ }^{98}$ These deficits critically compromise the normal development of mature decision-making abilities and will likely hyper-accentuate normative decision-making deficits in the adolescent age, placing these already vulnerable youth at a greater risk of becoming involved in delinquent activity.

\section{Discussion}

This review of the psychological and neurological development of decision-making reveals 5 key legal policy implications. First, there appears to be sufficient research to support the traditional theme to justify a legally distinct juvenile justice system because adolescents are inherently less capable of making rational and mature decisions compared to adults. In other words, developmental differences in decision-making increase the likelihood of participation in criminal behavior and reinforce the long-standing legal principle of diminished responsibility for a general category of offenders.

93 Teplin et al., Psychiatric disorders in youth in juvenile detention, 59 Archives of General Psychiatry (2002), pp. 1133-1143.

$94 \quad$ Robertson et al., Prevalence of mental illness and substance abuse disorders among incarcerated juvenile offenders in Mississippi, 35 Child Psychiatry and Human Development (2004), pp. 55-74.

95 McCuish et al., Psychopathic traits and offending trajectories from early adolescence to adulthood, 42 Journal of Criminal Justice (2014), pp. 66-76; Supra, note 56, Salekin and Lynman (2010) ff.

96 Reiss and Roth, Understanding and preventing violence: Panel on the understanding and control of violent behavior, Vol. 1 (National Academy Press 1993)

97 Farrington, The family backgrounds of aggressive youths, in Aggression and anti-social behavior in childhood and adolescence, eds. Hersov, Berger, and Shaffer (Pergamon Press 1978), pp. 73-93; Manly et al., The impact of subtype, frequency, chronicity, and severity of child maltreatment on social competence and behavior problems, 6 Developmental Psychology (1994), pp. 121-143; Seto and Lalumière, What is so special about male adolescent sexual offending? A review and test of explanations through meta-analysis, 136(4) Psychological Bulletin (2010), pp. 526-575.

98 Moffitt et al., Neuropsychological tests predict persistent male delinquency, 32(2) Criminology (1994), pp. 101-124. 
Second, with regards to the age of criminal responsibility, the research on basic cognitive decision-making capacities suggests that the ability to accurately assess the risks and benefits of a decision are not fully developed until middle adolescence, approximately 16 years of age. In addition to these cognitive deficits, children and adolescents under the age of 16 also typically have underdeveloped psychosocial capacities. Accordingly, those under the age of 16 years exhibit the poorest decision-making skills, and, consequently are at the greatest risk for risk-taking and criminal activity. More specifically, these individuals exhibit, on average, less ability to accurately identify the risks and benefits of a given situation and are unable to fully appreciate the immediate severity of their "criminal choices", as well as the long-term negative impacts to their victims and themselves. Further, these individuals are typically highly impulsive, are greatly influenced by antisocial peers, are hyper-focused on the potential rewards of a given decision, and are more likely to minimize the potential negative repercussions of their actions. Not surprisingly, the average age of a juvenile offender is 14-15 years of age. This age group begins to spend more time with their peers, are away from parental and other authority monitoring, and are most likely to encounter new, risky, and dangerous situations while having underdeveloped cognitive and psychosocial decision-making abilities. This pattern of findings lends support for a minimum age of criminal responsibility at 16 years within the juvenile justice system, such as is practiced in Sweden.

Third, for the age of majority theme, while cognitive decision-making typically is fully developed by 16 years of age, psychosocial capacities continue to develop well into early adulthood - approximately 24 years of age. Though the typical 18-year old can efficiently identify the risks and benefits associated with a decision, they still are susceptible to risky social/situational contexts (e.g., antisocial peers, social relationship stress, and threat ambiguity), and key psychological risk factors (e.g., impulsivity, hypersensitivity to reward, and reduced response to punishment). The developmental gap between cognitive decision-making and psychosocial factors, lasting until approximately the mid-twenties, is critical to understanding late adolescent risky decision-making, particularly, while adolescent decision-making is often dependent on the social context. This raises the possibility that the more appropriate maximum age for youth justice systems might be 24 years. Similar sentiments have been put forth by Professor D. F. Swaab, ${ }^{99}$ the renowned Dutch neuroscientist and former long-time director of the Netherlands Institute for Neuroscience (formerly Institute for Brain Research), who concluded on the basis of this institute's research and other neuroscientists that:

The development of the prefrontal cortex is a slow process, continuing until the age of 25. It's only at that age that an individual is fully equipped to control their impulses and make moral judgments... the age at which offenders are tried under adult criminal law shouldn't be reduced to, say, sixteen, as some politicians are urging in an effort to woo 
voters, but should rather be raised to an age at which brain structures are mature, at around twenty three to twenty five (p. 1168).

The fourth policy theme is competency. Until recently, adjudicative competence was infrequently raised within the juvenile justice system and, when raised, usually involved either one of two conditions: severe mental illness (e.g., psychosis) or mental retardation/ handicap. Accordingly, there has been little discussion amongst politicians and lawmakers as to whether developmental immaturity constitutes a legitimate legal argument for a judgment of incompetency and related legal themes. This review reveals a substantial gap with contemporary empirical literature on decision-making as related to competency and the law. Specifically, it is clear that the typical child and early adolescent (less than 13 years of age) do not possess the necessary decision-making capacities to be rendered competent under the standards clearly set out in Dusky v. United States (1960). Upon reaching 14 years of age, however, there is a progression toward greater competency-related abilities over the next two years until 16 years of age in which most adolescents exhibit the same levels of competency to stand trial as do adults. These findings suggest that for those jurisdictions with a minimum age of criminal responsibility below 13 years of age, competency to stand trial will likely be a critical factor throughout the trial procedure. Critically, however, while research indicates that upon researching 16 years of age, the typical adolescent is as competent as an adult defendant, the contemporary psychometric tools used to assess competency (e.g., Competency Screening Test (CST) ${ }^{100}$ and the MacArthur Competency Tool - Criminal Adjudication (MacCAT-CA)), ${ }^{101}$ are based on primarily cognitive decision-making models. In contrast, the psychosocial capacities in competency-related decisions have yet to be sufficiently addressed despite their importance for mature decision-making. This relationship is particularly important because late adolescents appear competent based on cognitive decision-making criteria, however as mentioned above, literature on psychosocial traits indicate that this age group exhibits a hyper-focus on the present moment, are impulsive, are highly influenced by antisocial peers, are highly influenced by new social contexts, and have a limited understanding of the costs of punishment. This research suggests that more fully developed or multi-domain competency instruments need to be formulated and utilized for jurisdictions where the age of criminal responsibility is below 16. In contrast, there appears to be insufficient research regarding late adolescent competency issues and the validity of related instruments.

Fifth, the most contentious issue yet is the criminal legal culpability of child and adolescent serious and violent offenders. Specifically, at what age is there confidence that sufficient cognitive and psychosocial capabilities exist to fully comprehend the consequences

100 Lipsitt et al., Competency for Trial: A screening instrument, 128 American Journal of Psychiatry (1971), pp. 105-109.

101 Supra, note 10, Poythress $2010 \mathrm{ff}$. 
of a major violent act? As previously mentioned, adolescents along with young adults (up to age 25), exhibit reduced decision-making capabilities, which is associated with poorer decision-making and greater risk-taking. Importantly, the majority of the above-mentioned research focuses on the psychological and neurological development in the typical adolescent. Of course, there is considerable individual variation in both the psychological and neurological bases of decision-making. Indeed, severe cognitive deficits, low IQ, and neurological abnormalities, as well as profound mental health and substance abuse problems typically characterize SVOs. In addition, a number of personality disorders common to juvenile detention facilities (e.g., APSD, Psychopathy), are also marked by neurological deficits. These risk factors have direct influences on decision-making capacities and greatly exacerbate an already vulnerable system, placing these individuals at a particular risk of serious criminal behavior. Critically, and, as mentioned previously, risk factors for many serious and violent offenders begin early in development (i.e., within the pre/perinatal developmental period). Therefore, it is possible that early interventions (e.g., home nurse visitations) may greatly benefit these individuals. Further, as previously mentioned, ethnic minority members are consistently overrepresented within juvenile detention facilities throughout the world. In effect, criminal courts, with their punitive focus when judging adolescents and young adults, have been criminalizing individuals predominantly suffering from neurological deficits, who would be more appropriately handled through health care treatments.

\section{Conclusion}

The main theme of this article has focused on considering the implications of the most recent research on the psychological and neurobiological bases of several key assumptions of juvenile justice systems in advanced Western industrial liberal democratic countries. Given the rapidly evolving and groundbreaking research discussed above and the enormous complexities of all developmental theoretical models of serious and violent offending, the recommendations in this article are necessarily tentative. Nonetheless, this research will hopefully stimulate a serious discussion of key legal assumptions evident in most contemporary juvenile justice systems. There is little doubt that, apart from several state jurisdictions in the US, few other countries have recent histories of incarcerating young offenders and young adults in large numbers and/or for lengthy periods. Even among the traditionally more punitive and deterrence oriented US states such as Texas and New York, there has been a recent downward trend in custody use. Part of this encouraging change appears related to a recognition by politicians and senior juvenile justice policy officials of the complex empirical research and development in theory, some of which has been discussed here, which illustrates why the enormously costly juvenile justice systems based on adult criminal justice principles has neither reduced serious vi- 
olent recidivism nor deterred others from such crimes. ${ }^{102}$ Yet, despite declining use of incarceration within the US, there is little evidence that the current psychological and neurological research has even been considered or debated among politicians with regards to raising the minimum age of responsibility to mid-adolescence and the age of majority to age 23-24, or the implications of this research for juvenile competency to stand trial.

102 Carrington, Trends in serious and violent youth crime in Canada, 1986-2011, in Serious and Violent Young Offenders and Youth Criminal Justice: A Canadian Perspective, eds. Corrado, Leschied, and Lussier (Simon Fraser University Press, forthcoming in 2014); Supra, note 3 Cook and Roesch $2012 \mathrm{ff}$. 


\section{Appendix A. Definitions of key neuroscience terms.}

\begin{tabular}{|c|c|}
\hline Labels & Definition \\
\hline Neuron & $\begin{array}{l}\text { A cell within the nervous system that processes and transmits information via electrical and } \\
\text { chemical signals to adjacent cells. Four key structures of the neuron are: 1) cell body, 2) dendrites } \\
\text { (i.e., branches of the cell where information comes in), 3) axon (i.e., carries information from the } \\
\text { cell body to the terminal buttons), and 4) terminal buttons (i.e., located at the end of the axon, } \\
\text { responsible for the release of chemicals, i.e., neurotransmitters, to adjacent cells) }\end{array}$ \\
\hline White matter & $\begin{array}{l}\text { A type of neuron in which the axon is covered by a myelin sheath. The myelin sheath acts as } \\
\text { a protective layer around the axon and allows for more efficient transmission of the electrical } \\
\text { signal across the axon from the cell body to the terminal button. In other words, it allows for a } \\
\text { more efficient communication of information between neurons. The term "white" in white matter } \\
\text { comes from the fact that the myelin sheath gives the neuron a white appearance. }\end{array}$ \\
\hline Grey matter & $\begin{array}{l}\text { A neuron that does not have a myelin sheath around its axon. Accordingly, these neurons have } \\
\text { slower, less efficient, rates of communication. }\end{array}$ \\
\hline Synaptic Pruning & $\begin{array}{l}\text { The elimination of axons/synapses. The purpose is to create more efficient networks of neurons. The } \\
\text { pruning process is governed by both normative biological processes, as well as by environmental } \\
\text { influence (i.e., "use it or lose it"). In this sense, synaptic pruning is shaped by experience and } \\
\text { learning. }\end{array}$ \\
\hline Neurotransmitters & $\begin{array}{l}\text { Chemical signals released from the terminal button of an axon, which stimulate, and, therefore } \\
\text { transmit, information to adjacent neurons. There are many different types of neurotransmitters } \\
\text { (e.g., dopamine, serotonin) that are located in different pathways throughout the brain. } \\
\text { Neurotransmitters have various functions such as mood, hunger, sleep cycles, and movement, } \\
\text { among others }\end{array}$ \\
\hline Dopamine & $\begin{array}{l}\text { A type of neurotransmitter that has an important role in arousal and motor control, and, of } \\
\text { particular importance here, in reward-motivated behavior. }\end{array}$ \\
\hline Neural network & $\begin{array}{l}\text { A series of interconnected neurons, which acts as its own functional entity and can regulate its } \\
\text { own activity via feedback, loops. Neural networks are responsible for more complex task-specific } \\
\text { processing than any individual cell. }\end{array}$ \\
\hline Hormones & $\begin{array}{l}\text { Molecules that are transported through the circulatory (i.e., blood) system and regulate physiology } \\
\text { and behavior. }\end{array}$ \\
\hline Testosterone & $\begin{array}{l}\text { A type of hormone that is secreted primarily from the testicles in males and the ovaries in females. } \\
\text { Within men it is has been linked to aggression and dominance. }\end{array}$ \\
\hline Cortisol & $\begin{array}{l}\text { A type of hormone that is secreted in time of stress and is linked to the body's fight-or-flight } \\
\text { system. Low levels of cortisol is an indication of low stress/low fear. }\end{array}$ \\
\hline Oxytocin & $\begin{array}{l}\text { A type of hormone that is responsible for social behaviors, particularly those involving sexual } \\
\text { reproduction, such as social recognition, pair bonding, orgasm, trust, and empathy. }\end{array}$ \\
\hline \multicolumn{2}{|l|}{ Brain Regions } \\
\hline Prefrontal Cortex & $\begin{array}{l}\text { Located in the front part of the brain (i.e., frontal lobe) and is responsible for planning, decision- } \\
\text { making, and the moderation of social behavior, among other functions. }\end{array}$ \\
\hline Limbic System & $\begin{array}{l}\text { Located in the middle of the brain and is composed of a number of interconnected brain structures } \\
\text { such as the olfactory bulbs, hippocampus, amygdala, and the limbic cortex, among other regions. } \\
\text { Some of the key functions within the limbic system are long-term memory, emotion, and } \\
\text { motivation. }\end{array}$ \\
\hline
\end{tabular}

